\title{
Pikkuvasikoiden käyttäytyminen iglukasvatuksessa
}

\author{
Leena Tuomisto ${ }^{1)}$, Anni Tarkiainen ${ }^{2)}$ Auvo Sairanen ${ }^{1)}$ ja Arto Huuskonen ${ }^{3)}$ \\ ${ }^{1)}$ Maa- ja elintarviketalouden tutkimuskeskus, Kotieläintuotannon tutkimus, Halolantie 31 A, 71750 \\ Maaninka,leena.tuomisto@mtt.fi,auvo.sairanen@mtt.fi \\ ${ }^{2)}$ Kuopion yliopisto, Biotieteiden laitos, PL 1627, 70211 Kuopio, anni.tarkiainen@uef.fi \\ ${ }^{3)}$ Maa- ja elintarviketalouden tutkimuskeskus, Kotieläintuotannon tutkimus, Tutkimusasemantie 15, \\ 92400 Ruukki,arto.huuskonen@mtt.fi
}

\section{Tiivistelmä}

Pikkuvasikoiden iglukasvatuksella tavoitellaan terveempiä vasikoita siirtämällä vasikat pian syntymän jälkeen navettarakennuksen ulkopuolelle igluihin pienempään tautipaineeseen. Kokeemme tarkoituksena oli verrata vasikoiden käyttäytymistä iglukasvatuksessa ja perinteisessä sisäkasvatuksessa. Koe tehtiin MTT Maaningan toimipaikassa maalis-kesäkuussa 2009. Kokeen 19 sonnivasikkaa ja 13 lehmävasikkaa syntyivät helmi-huhtikuussa. Koekäsittelyt olivat 1 ) kasvatus ulkona iglussa (2 vasikkaa/iglu), 2) kasvatus sisäkarsinassa lämpimässä navetassa (2 vasikkaa/karsina). Vasikkaiglut olivat $1,2 \times 2,0 \mathrm{~m}$ ja niiden edessä oli etukarsina $1,2 \times 1,5 \mathrm{~m}$. Sisäkarsinat $(1,2 \times 3,0 \mathrm{~m})$ oli muodostettu yhdistämällä kolme yksittäiskarsinaa. Igluissa ja karsinoissa käytettiin kuivikkeena olkea. Vasikat siirrettiin koeympäristöihin pareittain sitä mukaa kuin ne syntyivät. Kokeen alkaessa vasikat olivat 4,3 $\pm 1,7$ vrk ikäisiä ja kokeen päättyessä 73,5 $\pm 1,6$ vrk ikäisiä. Vasikoille tarjottiin lämmintä hapanjuomaa tuttisangoista $8 \mathrm{l} / \mathrm{vrk}$. Vasikat saivat vapaasti kuivaa heinää sekä teollista täysrehua korkeintaan 3 $\mathrm{kg} / \mathrm{vrk} / \mathrm{eläin}$. Igluissa lämpötila vaihteli $-16,5{ }^{\circ} \mathrm{C}$ ja $+35,7{ }^{\circ} \mathrm{C}$ välillä ja sisäkarsinoissa $+10,1{ }^{\circ} \mathrm{C}$ ja $+25,1{ }^{\circ} \mathrm{C}$ välillä. Vasikoiden käyttäytymistä videokuvattiin viikoittain kahden vuorokauden ajan. Käyttäytymistoiminnot analysointiin videonahoilta hetkellisellä seurannalla käyttäen 15-20 minuutin otantaväliä. Igluvasikat käyttivät rehun syömiseen vähemmän aikaa kuin sisävasikat (3,6 vs. 4,8 \% vuorokauden havainnoista, $\mathrm{P}<0,05)$. Tämä havainto tukee tuotantotuloksia ja terveystuloksia, joiden mukaan igluvasikat söivät kokeen aikana vähemmän väkirehua ja heinää kuin igluvasikat ja sairastivat ripulia useammin kuin sisävasikat. Syömiseltä säästyneen ajan igluvasikat käyttivät passiivisena seisomiseen (igluvasikat 5,8 vs. sisävasikat $4,4 \%$ vuorokauden havainnoista, $\mathrm{P}<0,01$ ). Sisävasikoilla havaittiin enemmän rakenteiden ja huvitutin manipuloimista kuin igluvasikoilla (2,1 vs. 1,3\% vuorokauden havainnoista). Veden juomiseen, hapanjuoman juomiseen, toisen eläimen imemiseen, sosiaaliseen nuolemiseen, leikkimiseen, kävelemiseen, aktiivisena seisomiseen ja makaamiseen käytetyissä ajoissa ei ollut eroa kasvatusympäristöjen välillä $(\mathrm{P}>0,05)$. Igluvasikat makasivat lähes yksinomaan igluissa ja viettivät etukarsinassa keskimäärin $18 \%$ ajastaan. Käyttäytymishavainnot yhdessä tuotantotulosten kanssa viittaavat siihen, että rehuastioiden sijainti iglujen ulkopuolella etukarsinassa oli ongelmallinen. Vasikoiden ulkokasvatuksessa rehuastioiden sijoittamiseen tulee kiinnittää huomiota, jotta sääolosuhteet eivät pääse vaikuttamaan vasikoille tarjolla olevan rehun laatuun ja vasikoiden syömiskäyttäytymiseen.

Asiasanat: vasikat, kasvatusympäristöt, kylmäkasvatus, iglut, käyttäytyminen 


\section{Johdanto}

Perinteiset vasikoiden kasvatustilat ja hoitomenetelmät ovat usein monin tavoin puutteellisia eläimen terveyden ja hyvinvoinnin kannalta. Heikot olosuhteet altistavat vasikoita erityisesti hengitysteiden sairauksille ja suolistoperäisille sairauksille (Andrews 1992, van der Fels-Klerx ym. 2000). Pikkuvasikoiden iglukasvatuksella tavoitellaan terveempiä vasikoita siirtämällä vasikat pian syntymän jälkeen navettarakennuksen ulkopuolelle igluihin pienempään tautipaineeseen. Suomessa pikkuvasikoiden iglukasvatus on melko uusi kasvatusmuoto ja sitä harjoitetaan laajemmassa mittakaavassa vain muutamilla tiloilla. Pienten vasikoiden kasvattaminen kylmässä herättää usein huolta eläinten terveydestä ja hyvinvoinnista. Kokeemme tarkoituksena oli verrata vasikoiden hyvinvointia iglukasvatuksessa ja perinteisessä sisäkasvatuksessa käyttäen mittareina eläinten kasvua, terveyttä ja käyttäytymistä. Tässä raportoidaan kokeen käyttäytymistutkimuksen tulokset. Kasvu- ja terveystulokset on raportoitu aiemmin (Tuomisto ym. 2010).

Tässä raportoitu tutkimus on osa Maa- ja elintarviketalouden tutkimuskeskuksen (MTT) hallinnoimaa InnoNauta Kehitys -hanketta. InnoNauta -hankkeet ovat saaneet rahoitusta Euroopan maaseudun kehittämisen Maatalousrahastosta. Tuki on myönnetty hankealueiden ELY-keskusten toimesta. Hankkeiden yhteistyökumppaneina toimivat TTS tutkimus, AtriaNauta ja Valio Oy.

\section{Aineisto ja menetelmät}

Tutkimus tehtiin MTT Maaningan toimipaikassa keväällä 2009. Koe alkoi 2.3.2009 ja päättyi 1.7.2009. Kokeessa käytetyt 19 holstein-rotuista sonnivasikkaa ja 13 holstein-rotuista lehmävasikkaa syntyivät helmi-huhtikuussa MTT Maaningan tutkimusnavetassa. Koekäsittelyt olivat 1) kasvatus ulkona vasikkaiglussa (2 vasikkaa/iglu, igluvasikat), 2) kasvatus sisäkarsinassa lämpimässä navetassa (2 vasikkaa/karsina, sisävasikat). Vasikkaiglut olivat kooltaan $120 \times 200 \mathrm{~cm}$ ja niiden edessä oli etukarsina $120 \times 150 \mathrm{~cm}$ (tilaa yhteensä $2,1 \mathrm{~m}^{2} / \mathrm{eläin}$ ). Vasikkaiglut oli sijoitettu suojaisalle sisäpihalle. Lämpimän navetan sisäkarsinat $(120 \times 305 \mathrm{~cm}$, tilaa 1,8 m²/eläin) oli muodostettu yhdistämällä kolme yksittäiskarsinaa. Sisäkarsinoiden puuritiläpohjat oli peitetty kumimatoilla. Igluissa ja karsinoissa käytettiin kuivikkeena olkea. Sisäkarsinoissa lisälämmönlähteenä käytettiin karsinan yläpuolelle kiinnitettäviä lämpölamppuja (1 lamppu/karsina) vasikoiden neljän viikon ikään asti.

Iglujen sisällä keskilämpötila oli maaliskuussa $-1,7^{\circ} \mathrm{C}$, huhtikuussa $+3,8^{\circ} \mathrm{C}$, toukokuussa $+13,1$ ${ }^{\circ} \mathrm{C}$ ja kesäkuussa $+15,3{ }^{\circ} \mathrm{C}$ (Tuomisto ym. 2010). Alin igluissa mitattu lämpötila oli $-16,5^{\circ} \mathrm{C}$ ja korkein $+35,7^{\circ} \mathrm{C}$. Sisäkarsinoissa keskilämpötila oli maaliskuussa ja huhtikuussa $+14,5^{\circ} \mathrm{C}$, toukokuussa $+17,9{ }^{\circ} \mathrm{C}$ ja kesäkuussa $+18,4{ }^{\circ} \mathrm{C}$. Alin sisäkarsinoissa mitattu lämpötila oli $+10,1{ }^{\circ} \mathrm{C}$ ja korkein $+25,1$ ${ }^{\circ} \mathrm{C}$.

Kaikki vastasyntyneet vasikat siirrettiin syntymän jälkeen yksittäiskarsinoihin lämpölampun alle. Lämpölamppu poistettiin igluihin siirrettäviltä vasikoilta vuorokauden kuluttua syntymästä. Koeryhmiin jakoa varten odotettiin, että navettaan syntyi kaksi vasikkaa. Vasikat siirrettiin pareittain koeympäristöihin sitä mukaa kuin ne syntyivät nuoremman vasikan ollessa noin kolmen vuorokauden ikäinen. Vasikat myös lopettivat kokeessa pareittain sitä mukaa kuin 10 viikkoa koetta tuli täyteen. Igluvasikoilla käytettiin igluihin siirron jälkeisinä kahtena ensimmäisenä päivänä lämpöliivejä. Kokeen alkaessa vasikat olivat 4,3 $\pm 1,7$ (keskiarvo \pm keskihajonta) vuorokauden ikäisiä ja päättyessä $73,5 \pm 1,6$ vuorokauden ikäisiä.

Vastasyntyneille vasikoille tarjottiin ternimaitoa kolmen päivän ajan. Seuraavien kahden päivän aikana vasikat totutettiin vähitellen hapatettuun juomaan. Hapanjuoma valmistettiin maidosta AIVhapolla hapattamalla ja tarjottiin vasikoille lämpimänä $\left(+35^{\circ} \mathrm{C}\right)$ tuttisangoista aluksi $7,5 \mathrm{l} / \mathrm{vrk}$ ja kahden viikon iästä alkaen 8 1/vrk. Kahden viikon pituinen juotolta vieroitus alkoi vasikoiden seitsemän viikon iässä. Juoton ajaksi vasikat kytkettiin kiinni, jotta toisen eläimen juoman varastaminen estyi. Tuttisangot kerättiin pois noin 15 minuutin kuluttua juotosta. Vasikat saivat koko kokeen ajan vapaasti kuivaa heinää sekä teollista täysrehua (Raision Mullin-Herkku 1) korkeintaan $3 \mathrm{~kg} / \mathrm{vrk} / \mathrm{eläin.} \mathrm{Juoma-}$ vesiastiat täytettiin kolmesti päivässä juottojen yhteydessä. Talviaikana vesi tarjottiin lämpimänä. Vasikoille annettiin vitamiinivalmistetta (ADE Plus) $5 \mathrm{ml}$ kerran viikossa. Sisäkarsinoissa juomavesi, heinä ja väkirehu tarjottiin kukin omasta ämpäristään. Igluissa juomavesi ja heinä tarjottiin omista ämpäreistään ja väkirehu katetusta väkirehuastiasta. Igluissa rehuastiat sijaitsivat etukarsinassa. Jokaiseen igluun ja karsinaan oli kiinnitetty huvitutti. Karsinoita ja igluja kuivitettiin oljella useita kertoja viikossa. 
Vasikoiden käyttäytymistä videokuvattiin aikaviivenauhoituksella viikoittain kahden vuorokauden ajan. Tarkkailumenetelmänä käytettiin hetkellistä seurantaa 15-20 minuutin otantavälillä (Martin ja Bateson 1993). Kussakin havaintopisteessä vasikoiden toiminto ja asento havainnoitiin taulukossa 1 esitetyn luokittelun mukaisesti. Märehtimistä ei havainnoitu.

Taulukko 1. Käyttäytymisseurannoissa havainnoidut toiminnot ja niiden kuvaukset.

\begin{tabular}{|c|c|}
\hline Käyttäytyminen & Kuvaus \\
\hline Makaa yhteensä & Vasikka makaa tai on asettumassa makuulle \\
\hline Syö heinää tai väkirehua & Vasikka hamuaa suuhunsa, pureskelee tai nielee heinää tai väkirehua \\
\hline Juo vettä & Vasikka juo vettä tai loiskii vettä kielellä \\
\hline Juo hapanjuomaa & Vasikka imee hapanjuomaa tuttisankosta, manipuloi tuttia, puskee tuttisankoa \\
\hline Manipuloi rakenteita & Vasikka imee, puree tai nuolee huvituttia tai karsinan tai iglun rakenteita \\
\hline Imee toista eläintä & Vasikka imee toisen eläimen napaa, häntää, korvia tai kaulapantaa \\
\hline Nuolee toista eläintä & Vasikka nuolee tai maistelee toista eläintä \\
\hline Leikkii & Vasikka puskee otsallaan toista eläintä tai laukkaa tai hyppii leikkisästi \\
\hline Kävelee & Vasikka kävelee \\
\hline Seisoo aktiivisena & $\begin{array}{l}\text { Vasikka on seisaallaan, samanaikainen toiminto on jokin muu kuin yllä lueteltu, } \\
\text { esim. tutkiskelu, turkin hoito, nouseminen seisaalle }\end{array}$ \\
\hline Seisoo passiivisena & Vasikka on seisaallaan, ei havaittavaa toimintoa \\
\hline Makaa joutilaana $^{a}$ & $\begin{array}{l}\text { Vasikka on makuulla, ei havaittavaa toimintoa tai samanaikainen toiminto on } \\
\text { jokin muu kuin yllä lueteltu, esim. tutkiskelu, turkin hoito, makuulle asettuminen }\end{array}$ \\
\hline Makaa iglussa & Igluvasikka makaa iglun sisällä \\
\hline Seisoo iglussa & Igluvasikka seisoo iglun sisällä \\
\hline Makaa etukarsinassa & Igluvasikka makaa iglun ulkopuolella etukarsinassa \\
\hline Seisoo etukarsinassa & Igluvasikka seisoo iglun ulkopuolella etukarsinassa \\
\hline
\end{tabular}

${ }^{a}$ Käyttäytyminen nimettiin joutilaana makaamiseksi, koska vain pienessä osassa havainnoista oli havaittavissa samanaikaisesti muu aktiivinen toiminto.

Muuttujien tilastollinen testaus tehtiin SPSS for Windows 14.0 -ohjelmalla. Tilastollisia analyyseja varten vasikat jaettiin kahteen ryhmään syntymäajankohdan perusteella. Talvivasikat aloittivat kokeessa 2.3.-22.3.2009 välisenä aikana ja lopettivat kokeessa 10.5.-31.5.2009 välisenä aikana. Kevätvasikat aloittivat kokeessa 30.3.-29.4.2009 välisenä aikana ja lopettivat kokeessa 8.6.-1.7.2009 välisenä aikana.

Käyttäytymishavaintojen tilastollisia analyyseja varten kunkin vasikan koeviikkojen 1-2, 3-4, 56, 7-8 ja 9-10 havainnot yhdistettiin. Käyttäytymistoimintojen testaus tehtiin lineaarisella sekamallilla. Sukupuolitekijä jätettiin pois lopullisesta mallista, koska sukupuoli ei vaikuttanut tilastollisesti merkitsevästi testattuihin muuttujiin. Mallissa kiinteinä tekijöinä olivat kasvatusympäristö (iglu, sisäkarsina), koeviikko (1-2, 3-4, 5-6, 7-8, 9-10), syntymäajankohta (talvivasikat, kevätvasikat) sekä näiden yhdysvaikutukset. Satunnaistekijöinä olivat karsina sekä koeviikko $\times$ karsina. Iglun ja etukarsinan käyttöön liittyviä muuttujia testattaessa käsittelyn vaikutus jätettiin pois mallista. Toistomittausten kovarianssirakenne (compound symmetry structure, heterogeneous compound symmetry structure, first-order autoregressive structure, heterogeneous first-order autoregressive structure, toeplitz structure, heterogenous toeplitz structure) valittiin Akaiken informaatiokriteerin perusteella. Mallin oletusten voimassaolo tarkastettiin ja tarvittaessa muuttujalle (x) tehtiin $\ln (\mathrm{x}+1)$ tai Box-Cox muuttujamuunnos (Box ja Cox 1964). Tulokset esitetään mallin estimoimina keskiarvoina ja hajontaa kuvaamaan käytetään keskiarvon keskivirhettä. Muuttujamuunnoksen avulla lasketuilla muuttujilla tulosten esittämisessä käytetään takaisinmuunnettuja arvoja. Mikäli mallin virhetermien normaalisuutta ja varianssien yhtäsuuruutta ei saavutettu muuttujamuunnoksella, tulokset esitetään keskiarvoina ja hajontaa kuvaamaan käytetään keskihajontaa.

\section{Tulokset ja tulosten tarkastelu}

Kylmissä olosuhteissa makuulla pysytteleminen voi olla vasikan keino säästää energiaa, sillä makuulla vasikan tarvitsee tuottaa lämpöä vähemmän kuin seisaalla (Schrama ym. 1993). Tutkimuksessamme vasikoiden makuuajassa ei ollut eroa kasvatusympäristöjen välillä. Vasikoiden keskimääräinen makuuaika, 72,8 \% vuorokaudesta, on lähellä muita saman ikäisiltä vasikoilta raportoituja makuuaikoja (esim. Bøe ja Havrevoll 1993). Makuulla vietetty aika väheni kahden ensimmäisen koeviikon jälkeen 
vasikoiden syömis- ja seisomisaktiivisuuden lisääntyessä. Vasikoiden energiantarpeen kasvaminen kokeen edetessä näkyi sekä lisääntyneenä rehun syöntinä (Tuomisto ym. 2010) että suurempana syömiseen käytettynä aikana. Hapanjuomalta vieroituksessa heinän ja väkirehun syömiseen käytetty aika lisääntyi voimakkaasti. Samalla hapanjuoman juomiseen käytetty aika luonnollisesti väheni.

Igluvasikat käyttivät syömiseen vähemmän aikaa kuin sisävasikat, mikä tukee vasikoiden rehun käytöstä ja kasvusta tehtyjä havaintoja. Vaikka odotimme, että iglukasvatus lisäisi igluvasikoiden energiantarvetta, igluvasikat söivät kokeen aikana vähemmän väkirehua ja heinää kuin sisävasikat (Tuomisto ym. 2010). Mahdollisesti ulkoilman kosteus tai kylmyys pääsi vaikuttamaan igluvasikoille tarjolla olleen rehun laatuun ja heikentämään sen maittavuutta. Sairastelu ja lämpötilan nouseminen korkeaksi suorassa auringonpaisteessa saattoivat ajoittain heikentää igluvasikoiden ruokahalua (Tuomisto ym. 2010). Lisäksi vallitseva säätila saattoi vaikuttaa vasikoiden halukkuuteen siirtyä etukarsinaan ruokailemaan. Hepola ym. (2006) ovat esittäneet, että kylmällä ilmalla vasikat saattavat energiaa säästääkseen välttää suojasta poistumista, myös syömään, mikäli rehuastiat sijaitsevat suojan ulkopuolella. Havainto, että talvivasikat käyttivät rehun syömiseen enemmän aikaa kuin kevätvasikat, on ristiriidassa edellä esitettyjen teorioiden kanssa. Rehun syönnistä tehtyjen havaintojen mukaan kevätvasikat kuluttivat rehua enemmän kuin talvivasikat (Tuomisto ym. 2010).

Käyttäytymisseurantojen mukaan vasikat joivat tai maistelivat vettä tasaisesti koko kokeen ajan. Ennen vieroitusta vasikoiden vedenkulutus on rajoitetulla juotolla alle 2 litraa/vrk, mutta kasvaa voimakkaasti vieroituksessa (Kertz ym. 1984, Huuskonen ym. 2011). Vasikoiden juomiseen käyttämässä ajassa tämä ei tutkimuksessamme selkeästi näkynyt.

Toisen eläimen imemistä havaittiin harvoin eikä sen määrässä ollut eroa kasvatusympäristöjen välillä. Suuri osa imemisestä kohdistui toisen eläimen kaulapantaan, mikä ei ole yhtä haitallista kuin ruumiinosiin kohdistuva imeminen. Sisävasikat manipuloivat suullaan (imee, nuolee, nakertaa) rakenteita tai huvituttia enemmän kuin igluvasikat. Myös Hepola ym. (2006) havaitsivat, että ulkokasvatetut vasikat manipuloivat rakenteita vähemmän kuin sisäkasvatuksessa olleet eläimet. He epäilivät, että ulkokasvatuksessa olleet eläimet pystyivät tyydyttämään tutkiskeluntarvettaan myös visuaalisesti, koska ulkokasvatettujen eläinten karsinan ympäristö oli vaihtelevampi.

Sosiaalisen nuolemisen tai leikin määrissä ei ilmennyt eroa kasvatusympäristöjen välillä. Vasikoiden juoksuleikki koostuu tilaa vievistä liikesarjoista, kuten hyppelystä, kirmaamisesta, potkuista. Leikki väheni kokeen lopussa, mikä voi osittain johtua karsinan tai iglun käymisestä ahtaammaksi eläinten kasvaessa. Jensen ja Kyhn (2000) havaitsivat vasikoilla juoksuleikkiä enemmän viiden viikon iässä kuin seitsemän tai yhdeksän viikon iässä, joten juoksuleikin vähentyminen voi liittyä myös vasikoiden normaaliin kehitykseen. Kokeessamme karsinan tai iglun käyminen ahtaaksi eläinten kasvaessa saattoi vaikuttaa myös vasikoiden kävelemisaktiivisuuden vähenemiseen kokeen lopussa.

Igluvasikat seisoivat passiivisena enemmän kuin sisävasikat. Lyhyemmän syömiseen käytetyn ajan vuoksi igluvasikoille nähtävästi jäi sisävasikoita enemmän aikaa passiivisena seisoskeluun. Igluja sisävasikoiden välillä ei ollut eroa seisaalla aktiivisena tai joutilaana makuulla vietettyyn aikaan.

Igluvasikat makasivat lähes yksinomaan iglujen sisällä sekä talvella että kesällä. Igluissa käytettiin kuivikkeena paksua kerrosta olkea, jonka on useissa preferenssikokeissa todettu olevan naudan mielestä mieluisin lattiamateriaali (Lowe ym 2001, Manninen ym. 2002). Olkipohja on pehmeä, pitävä ja eristävä. Lisäksi iglu tarjosi vasikoille sateensuojan ja suojan voimakasta tuulta vastaan. Etukarsinassa vietetty aika lisääntyi kahden ensimmäisen koeviikon jälkeen, mikä selittyy vasikoiden aktiivisuuden lisääntymisellä. Kokeen viimeisten kahden viikon aikana etukarsinassa oleskelua havaittiin eniten. On mahdollista, että kokeen loppupuolella molempien vasikoiden samanaikainen oleskelu iglun sisällä kävi hankalaksi, jolloin ainakin toinen vasikka hakeutui useammin etukarsinaan. Myös vieroituksesta johtuva karkea- ja väkirehun syönnin voimakas kasvaminen ohjasi vasikoita useammin oleskelemaan etukarsinassa kokeen loppupuolella. 
Taulukko 2. Vasikoiden eri toimintoihin käyttämä aika prosentteina kaikista käyttäytymishavainnoista klo 00:00-24:00 välisenä aikana (keskiarvo).

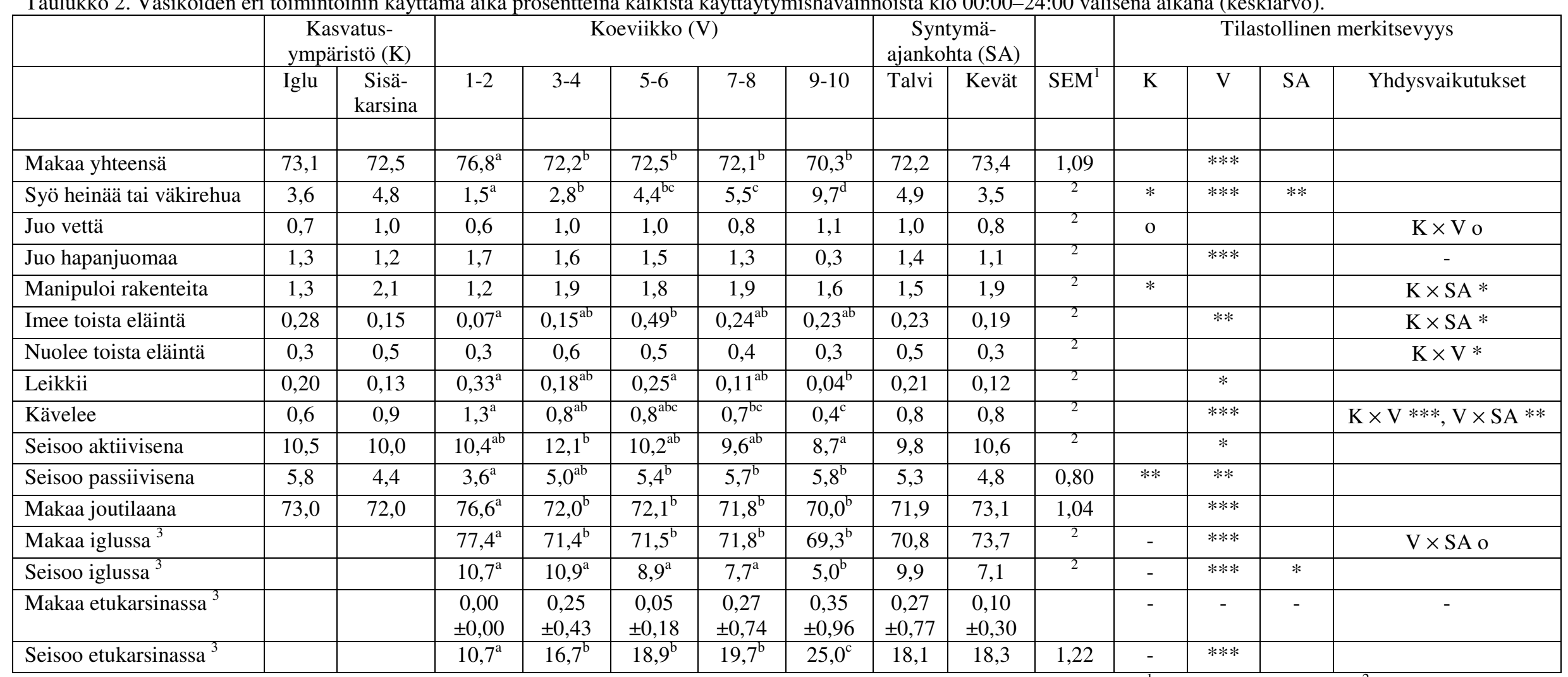

Eri kirjaimet $(\mathrm{a}, \mathrm{b}, \mathrm{c})$ tarkoittavat, että toimintoon käytetty aika eroaa koeviikkojen välillä tilastollisesti merkitsevästi $(\mathrm{P}<0,05)$. ${ }^{\mathrm{I}}$ Keskiarvon keskivirhe, ${ }^{2}$ Muuttujamuunnoksen vuoksi keskiarvon keskivirhettä ei voida esittää, ${ }^{3}$ Testauksessa mukana vain igluvasikat, - Ei testattu. 


\section{Johtopäätökset}

Igluvasikat käyttivät rehun syömiseen ja rakenteiden manipuloimiseen vähemmän aikaa ja passiivisena seisomiseen enemmän aikaa kuin sisävasikat. Muilta osin iglu- ja sisävasikoiden aikabudjetit olivat hyvin lähellä toisiaan. Käyttäytymishavainnot yhdessä tuotantotulosten kanssa viittaavat siihen, että rehuastioiden sijainti iglujen ulkopuolella etukarsinassa oli ongelmallinen. Vasikoiden ulkokasvatuksessa rehuastioiden sijoittamiseen tulee kiinnittää huomiota, jotta sääolosuhteet eivät pääse vaikuttamaan vasikoille tarjolla olevan rehun laatuun ja vasikoiden syömiskäyttäytymiseen.

\section{Kirjallisuus}

Andrews, A.H. 1992. Calf respiratory disease. Teoksessa: Andrews, A.H., Blowey, R.W., Boyd, H. \& Eddy, R.G. (toim.). Bovine medicine: diseases and husbandry. Oxford: Blackwell Scientific Publications Ltd. $202-$ 212.

Bøe, K. \& Havrevoll, Ø. 1993. Cold housing and computer-controlled milk feeding for dairy calves: behaviour and performance. Anim. Prod. 57: 183-191.

Box, G.E.P. \& Cox, D.R. 1964. An analysis of transformations. J. Roy. Statist. Soc. Ser. B 26, 211-252.

Fels-Klerx, H.J. van der, Horst, H.S. \& Dijkhuizen, A.A. 2000. Risk factors for bovine respiratory disease in dairy youngstock in The Netherlands: the perception of experts. Livest. Prod. Sci. 66: 35-46.

Hepola, H., Hänninen, L., Pursiainen, P., Tuure, V.-M., Syrjälä-Qvist, L., Pyykkönen, M. \& Saloniemi, H. 2006. Feed intake and oral behaviour of dairy calves housed individually or in groups in warm or cold buildings. Livest. Sci. 105: 94-104.

Huuskonen, A., Tuomisto, L. \& Kauppinen, R. 2011. Effect of drinking water temperature on water intake and performance of dairy calves. J. Dairy Sci. 94: 2475-2480.

Jensen, M. B. \& Kyhn, R. 2000. Play behaviour in group-housed dairy calves, the effect of space allowance. Appl. Anim. Behav. Sci. 67: 35-46.

Kertz, A.F., Reutzel, L.F. \& Mahoney, J.H. 1984. Ad libitum water intake by neonatal calves and its relationship to calf starter intake, weight gain, feces score, and season. J. Dairy Sci. 67: 2964-2969.

Lowe, D. E., Steen, R. W. J. \& Beattie, V. E. 2001. Preferences of housed finishing beef cattle for different floor types. Anim. Welf. 10: 395-404.

Manninen, E., de Passillé, A. M., Rushen, J., Norring, M. \& Saloniemi, H. 2002. Preferences of dairy cows kept in unheated buildings for different kind of cubicle flooring. Appl. Anim. Behav. Sci. 75: 281-292.

Martin P \& Bateson P, 1993. Measuring behaviour. An introductory guide. Toinen painos. Cambridge press. United Kingdom. $222 \mathrm{~s}$.

Schrama, J.W., Arieli, A., Brandsma, H.A., Luiting, P. \& Verstegen, M.W.A. 1993. Thermal requirements of young calves during standing and lying. J. Anim. Sci. 71: 3285-3292.

Tuomisto, L., Sairanen, A., Huuskonen, A., Hartikainen, K., Tarkiainen, A. \& Kauppinen, R. 2010. Pikkuvasikoiden kasvu ja terveys iglukasvatuksessa. Julkaisussa: Maataloustieteen Päivät 2010 [verkkojulkaisu]. Suomen Maataloustieteellisen Seuran julkaisuja no 26. Toim. Anneli Hopponen. Viitattu [24.11.2011]. Julkaistu 11.1.2010. Saatavilla Internetissä: http://www.smts.fi (Pikkuvasikoiden kasvu ja terveys iglukasvatuksessa). ISBN 978-951-9041-54-4. 